\title{
High-Flow Nasal Cannulae in Very Preterm Infants after Extubation
}

\author{
Brett J. Manley, M.B., B.S., Louise S. Owen, M.D., Lex W. Doyle, M.D., \\ Chad C. Andersen, M.B., B.S., David W. Cartwright, M.B., B.S., \\ Margo A. Pritchard, Ph.D., Susan M. Donath, M.A., and Peter G. Davis, M.D.
}

\section{BACKGROUND}

The use of high-flow nasal cannulae is an increasingly popular alternative to nasal continuous positive airway pressure (CPAP) for noninvasive respiratory support of very preterm infants (gestational age, $<32$ weeks) after extubation. However, data on the efficacy or safety of such cannulae in this population are lacking.

\section{METHODS}

In this multicenter, randomized, noninferiority trial, we assigned 303 very preterm infants to receive treatment with either high-flow nasal cannulae (5 to 6 liters per minute) or nasal CPAP ( $7 \mathrm{~cm}$ of water) after extubation. The primary outcome was treatment failure within 7 days. Noninferiority was determined by calculating the absolute difference in the risk of the primary outcome; the margin of noninferiority was 20 percentage points. Infants in whom treatment with high-flow nasal cannulae failed could be treated with nasal CPAP; infants in whom nasal CPAP failed were reintubated.

\section{RESULTS}

The use of high-flow nasal cannulae was noninferior to the use of nasal CPAP, with treatment failure occurring in 52 of 152 infants (34.2\%) in the nasal-cannulae group and in 39 of 151 infants (25.8\%) in the CPAP group (risk difference, 8.4 percentage points; $95 \%$ confidence interval, -1.9 to 18.7). Almost half the infants in whom treatment with high-flow nasal cannulae failed were successfully treated with CPAP without reintubation. The incidence of nasal trauma was significantly lower in the nasal-cannulae group than in the CPAP group $(\mathrm{P}=0.01)$, but there were no significant differences in rates of serious adverse events or other complications.

\section{CONCLUSIONS}

Although the result for the primary outcome was close to the margin of noninferiority, the efficacy of high-flow nasal cannulae was similar to that of CPAP as respiratory support for very preterm infants after extubation. (Funded by the National Health and Medical Research Council; Australian New Zealand Clinical Trials Network number, ACTRN12610000166077.)

From the Newborn Research Centre, Royal Women's Hospital (B.J.M., L.S.O., L.W.D., P.G.D.), the Departments of Obstetrics and Gynaecology (B.J.M., L.S.O., L.W.D., P.G.D.) and Paediatrics (L.W.D., S.M.D.), University of Melbourne, and the Critical Care and Neurosciences Theme (B.J.M., L.S.O., L.W.D., P.G.D.) and Clinical Epidemiology and Biostatistics Unit (S.M.D.), Murdoch Children's Research Institute, Melbourne, VIC, the Department of Neonatal Medicine, Women's and Children's Hospital, Adelaide, SA (C.C.A.), and Women's and Newborn Services, Royal Brisbane and Women's Hospital (D.W.C., M.A.P.), the Department of Paediatrics and Child Health, University of Queensland (D.W.C.), and the University of Queensland Centre for Clinical Research (M.A.P.), Brisbane, QLD - all in Australia. Address reprint requests to Dr. Manley at the Newborn Research Centre, Level 7, Royal Women's Hospital, 20 Flemington Rd., Parkville, VIC 3052, Australia, or at brett.manley@thewomens.org.au.

N Engl J Med 2013;369:1425-33. DOI: 10.1056/NEJMoal300071 Copyright @ 2013 Massachusetts Medical Society. 
N THE UNITED STATES, APPROXIMATELY 75,000 infants were classified as very preterm (gestational age, <32 weeks) in 2011. ${ }^{1}$ Very preterm infants have substantially higher mortality and morbidity than term infants, partly because they are more prone to respiratory failure and often require mechanical ventilation through an endotracheal tube after birth. Once they recover from their acute breathing problems, the best way to achieve successful extubation from mechanical ventilation is controversial. Nasal continuous positive airway pressure (CPAP) is known to be superior to no positive-pressure support ${ }^{2}$ and is the current standard of care for noninvasive respiratory support of very preterm infants.

The use of high-flow nasal cannulae is an alternative means of providing noninvasive respiratory support to very preterm infants. Such cannulae deliver heated and humidified gas at flow rates of more than 1 liter per minute through small binasal prongs. Because high-flow nasal cannulae have a simpler interface with the infant and smaller prongs than nasal CPAP, the cannulae are perceived as easier to use, more comfortable for the infant, and advantageous for mother-infant bonding.3,4 The use of high-flow nasal cannulae is increasingly popular for noninvasive respiratory support in neonatal intensive care units around the world.3,5 In 2008, the devices were being used in up to two thirds of academic neonatal units in the United States. ${ }^{6}$ High-flow nasal cannulae are used to prevent extubation failure in preterm infants, with prescribed flow rates typically ranging from 2 to 8 liters per minute. ${ }^{3,7,8}$ However, there is little evidence regarding the risks and benefits of this new technique. ${ }^{9,10}$ Several mechanisms of action of high-flow nasal cannulae in preterm infants have been described, ${ }^{11}$ but the contribution of each is undefined. Furthermore, concern has been raised that the generation of unregulated distending pressure from high-flow nasal cannulae might injure the lungs. ${ }^{12,13}$

We hypothesized that high-flow nasal cannulae are an appropriate alternative to nasal CPAP, even if the devices do not provide superior respiratory support. We performed a multicenter, randomized, noninferiority trial of high-flow nasal cannulae, as compared with nasal CPAP, as respiratory support after extubation in preterm infants born at a gestational age of less than 32 weeks.

\section{METHODS}

\section{STUDY DESIGN AND OVERSIGHT}

From May 31, 2010, to July 3, 2012, we recruited infants in three Australian neonatal intensive care units at the Royal Women's Hospital, Melbourne; Women's and Children's Hospital, Adelaide; and the Royal Brisbane and Women's Hospital, Brisbane. The trial was designed and conducted by the authors. The human research ethics committee at each center approved the trial. The study was funded by the participating neonatal units and by the National Health and Medical Research Council. All authors vouch for the accuracy and completeness of the data and the fidelity of the study to the protocol, which is available with the full text of this article at NEJM.org. There was no commercial support for this study.

\section{PATIENTS}

Infants were eligible if they were born at a gestational age of less than 32 weeks, were receiving mechanical ventilation through an endotracheal tube, and were scheduled to undergo extubation for the first time to noninvasive respiratory support. Infants were ineligible if their gestational age was more than 36 weeks at the time of extubation, if they were participating in a concurrent study that prohibited inclusion, if they had a known major congenital anomaly that might affect breathing, or if maximal intensive care was not being provided. All parents or guardians provided written informed consent.

\section{RANDOMIZATION}

A computer-generated block-randomization sequence with random block sizes was used. All infants were stratified according to gestational age ( $<26$ weeks vs. $\geq 26$ weeks) and study center. Infants who were part of multiple births underwent individual randomization. Clinicians opened consecutively numbered, sealed, opaque envelopes immediately before extubation to determine the study-group assignment. In the case of an unplanned extubation in an infant for whom consent had already been obtained, randomization occurred if the treating physician decided to provide noninvasive respiratory support. If the infant required resuscitation and immediate reintubation, randomization did not occur, and the infant remained eligible for inclusion with the next planned extubation. 


\section{STUDY INTERVENTION}

Infants received oral or intravenous caffeine (either a loading dose of $20 \mathrm{mg}$ per kilogram of body weight or a maintenance dose of 5 to $10 \mathrm{mg}$ per kilogram) in the 24 hours before extubation. The treating physician made the decision to extubate an infant before randomization. Infants received their assigned treatment immediately after extubation. Treatment was considered to have failed if an infant who was receiving maximal respiratory support with the assigned treatment met one or more of the following four criteria for failure within 7 days after extubation: a fraction of inspired oxygen of 0.2 or more above the baseline value before extubation that was required to maintain a peripheral oxygen saturation of 88 to $92 \%$; a pH of less than 7.2 and a partial pressure of carbon dioxide of more than $60 \mathrm{~mm} \mathrm{Hg}$ on an arterial or free-flowing capillary blood gas sample; more than one apneic episode requiring intermittent positive-pressure ventilation within a 24-hour period or six or more apneic episodes requiring stimulation within 6 consecutive hours; or an urgent need for reintubation and mechanical ventilation, as determined by the treating physician.

Infants in the nasal-cannulae group were treated with the Optiflow device, which included the MR850 humidifier and binasal infant cannulae (Fisher \& Paykel Healthcare). Infants were fitted with prongs that maintained a leak at the nose, with the aim of occluding approximately half the nares. The device includes a pressurerelief valve that limits circuit pressure to $45 \mathrm{~cm}$ of water. The starting flow rate was based on the size of the prongs used, with 5 liters per minute for "premature" or "neonatal" prongs or 6 liters per minute for "infant," "intermediate infant," or "pediatric" prongs. Flow rates were altered at the physician's discretion in a stepwise fashion, with mandated limits between 2 liters per minute and the maximum recommended for the prong size: 6 liters per minute for "premature" and "neonatal" prongs, 7 liters per minute for "infant" or "intermediate infant" prongs, and 8 liters per minute for "pediatric" prongs. For infants who were weaned to 2 liters per minute and who had a fraction of inspired oxygen of less than 0.3 for more than 24 hours, treatment with the high-flow nasal cannulae could be stopped, although such cessation of therapy was not mandatory, and earlier cessation was or- dered at the discretion of the treating team if the fraction of inspired oxygen was less than 0.3.

Infants in whom treatment with high-flow nasal cannulae failed were treated with nasal CPAP (7 cm of water), with the same pressure limits as those used in the CPAP group. If the CPAP treatment failed under the maximal pressure during the first 7 days after extubation, infants were reintubated.

Infants in the CPAP group were started on a pressure of $7 \mathrm{~cm}$ of water with either binasal midline prongs (Fisher \& Paykel Healthcare) or subnasal prongs (Hudson RCI), depending on the practice in the individual unit. Nasal CPAP was generated with the use of a mechanical ventilator or an underwater "bubble" system. Pressures were altered at the physician's discretion, within limits of 5 to $8 \mathrm{~cm}$ of water during the first 7 days after extubation. Nonsynchronized nasal intermittent positive-pressure ventilation could be used at the time of extubation or at any later time during the admission, with a maximum inflating pressure of $25 \mathrm{~cm}$ of water and a maximum rate of 40 inflations per minute. Once infants were weaned to a nasal CPAP of $5 \mathrm{~cm}$ of water with a fraction of inspired oxygen of less than 0.3 for more than 24 hours, nasal CPAP could be discontinued. Infants in whom CPAP treatment failed at a maximal pressure of $8 \mathrm{~cm}$ of water (with or without nonsynchronized nasal intermittent positive-pressure ventilation) were reintubated. Infants in the CPAP group were not permitted to receive treatment with high-flow nasal cannulae at any time during their admission.

\section{STUDY OUTCOMES}

The primary outcome was treatment failure within 7 days (168 hours) after extubation. Prespecified secondary outcomes included reintubation during the primary-outcome period, death before hospital discharge, a requirement for supplemental oxygen at a gestational age of 36 weeks, pneumothorax after trial entry, total days of any respiratory support after trial entry, duration of oxygen supplementation after trial entry, and length of hospital admission. Nursing and medical staff members, who were aware of studygroup assignments, regularly assessed the nasal skin and septum for trauma caused by pressure from the binasal prongs. Data included the incidence of any nasal trauma, its cause, and the need for change of treatment because of nasal trauma. 


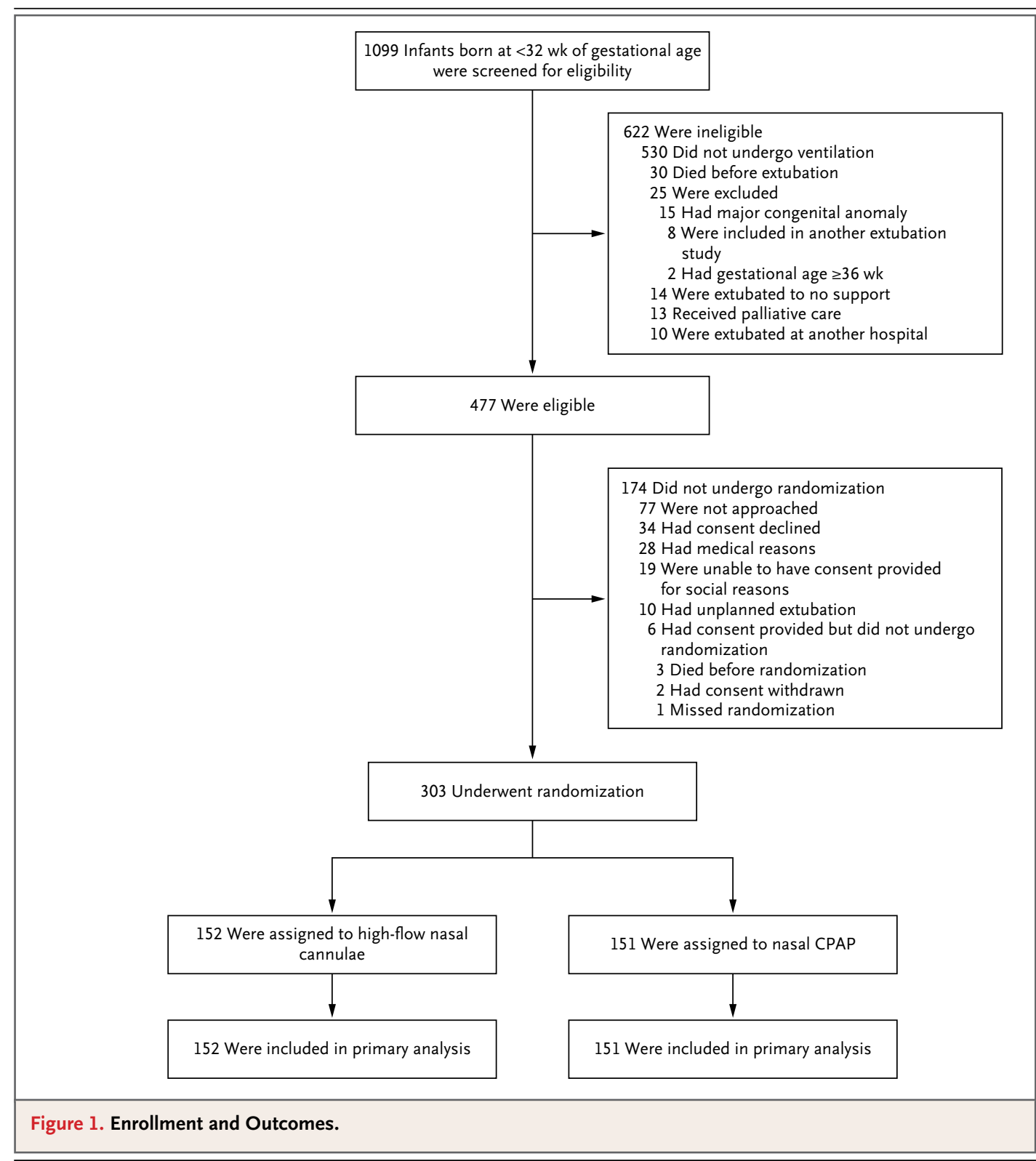

Serious adverse events were predefined as pneumothorax occurring while the infants received the assigned treatment and death. These events were reported to the principal investigator and the relevant ethics committee as they occurred. Data were collected until death or the first discharge home from the hospital.

\section{STATISTICAL ANALYSIS}

We estimated that extubation would have a failure rate of $25 \%$ for very preterm infants on the basis of a review of 2 years of data from the lead center (the Royal Women's Hospital, Melbourne), where high-flow nasal cannulae had not been used previously. We prespecified the margin of noninferiority for high-flow nasal cannulae as 20 percentage points above the failure rate for nasal CPAP. Since little guidance was available for such a comparison, the choice of margin was somewhat arbitrary. Our rationale was that many clinicians already strongly prefer the use of highflow nasal cannulae, and the devices are in widespread use because of their perceived benefits over nasal CPAP. We allowed the use of "rescue" nasal CPAP for infants in whom treatment with highflow nasal cannulae failed. This procedure reflected 


\begin{tabular}{|c|c|c|}
\hline Characteristic & $\begin{array}{l}\text { Nasal-Cannulae Group } \\
\qquad(\mathrm{N}=152)\end{array}$ & $\begin{array}{l}\text { CPAP Group } \\
(\mathrm{N}=151)\end{array}$ \\
\hline \multicolumn{3}{|l|}{ Mothers } \\
\hline White race - no. $(\%) \dagger$ & $127(83.6)$ & $120(79.5)$ \\
\hline Primigravida - no. (\%) & $61(40.1)$ & $59(39.1)$ \\
\hline Exposure to antenatal glucocorticoids - no. (\%) & $142(93.4)$ & $143(94.7)$ \\
\hline Cesarean section - no. (\%) & $101(66.4)$ & $101(66.9)$ \\
\hline \multicolumn{3}{|l|}{ Infants } \\
\hline \multicolumn{3}{|l|}{ Gestational age } \\
\hline No. of wk & $27.7 \pm 2.1$ & $27.5 \pm 1.9$ \\
\hline$<26$ wk - no. (\%) & $32(21.1)$ & $31(20.5)$ \\
\hline Birth weight $-\mathrm{g}$ & $1041 \pm 338$ & $1044 \pm 327$ \\
\hline Male sex — no. (\%) & $89(58.6)$ & $72(47.7)$ \\
\hline Multiple birth — no. (\%) & $49(32.2)$ & $52(34.4)$ \\
\hline Intubated in the delivery room - no. (\%) & $102(67.1)$ & $91(60.3)$ \\
\hline Median Apgar score at $5 \mathrm{~min}$ (IQR) & $7(6-8) \div$ & $8(6-8)$ \\
\hline Surfactant treatment - no. (\%) & $141(92.8)$ & $144(95.4)$ \\
\hline Caffeine treatment before extubation — no. (\%) & $151(99.3)$ & $148(98.0)$ \\
\hline Median postnatal age at extubation (IQR) $-\mathrm{hr}$ & $43.2(20.8-115.7)$ & $38.5(22.8-101.7)$ \\
\hline $\begin{array}{l}\text { Median duration of mechanical ventilation before } \\
\text { extubation (IQR) - hr }\end{array}$ & $36(19.5-101.5)$ & $36(20-93)$ \\
\hline $\mathrm{pH}$ before extubation $\sqrt{ }$ & $7.33 \pm 0.06$ & $7.32 \pm 0.06$ \\
\hline $\begin{array}{l}\text { Partial pressure of carbon dioxide before extubation - } \\
\qquad \mathrm{mm} \mathrm{Hg \mathbb { \int }}\end{array}$ & $44.2 \pm 9.2$ & $43.6 \pm 9.0$ \\
\hline Fraction of inspired oxygen before extubation & $0.23 \pm 0.04$ & $0.23 \pm 0.04$ \\
\hline \multicolumn{3}{|c|}{$\begin{array}{l}\text { Plus-minus values are means } \pm \text { SD. There were no significant differences between the two groups. CPAP denotes con- } \\
\text { tinuous positive airway pressure, and IQR interquartile range. } \\
\text { Race was reported by the investigators. } \\
\text { The Apgar score was not known for three infants. } \\
\text { S Blood gas results were from capillary (heel-prick) or arterial blood samples. }\end{array}$} \\
\hline
\end{tabular}

clinical practice around the world at centers where both treatments are commonly available.

The primary outcome was short-term treatment efficacy, rather than death or disability, for which a lower noninferiority margin might be recommended. ${ }^{14}$ Noninferiority was determined by calculating the absolute risk difference and $95 \%$ confidence interval for the primary outcome. For treatment with high-flow nasal cannulae to be noninferior, the upper limit of the $95 \%$ confidence interval had to be below 20 percentage points, and the lower limit of the $95 \%$ confidence interval had to be below zero. ${ }^{14} \mathrm{We}$ determined that a sample of 300 infants was required to show noninferiority for high-flow nasal cannulae with a power of $87 \%$.

All analyses were performed on an intention- to-treat basis, and infants remained in their assigned group for all outcomes. For the primary outcome and dichotomous secondary outcomes, we calculated the difference between the groups using risk differences and $95 \%$ confidence intervals. We used chi-square tests to compare secondary dichotomous outcomes and the appropriate parametric test (Student's t-test) or nonparametric test (Wilcoxon rank-sum test) to compare continuous outcomes. An independent data and safety monitoring committee performed two interim analyses, when the primary outcome was known for 100 infants and for 200 infants, and on the basis of each analysis recommended that the study continue unaltered. All analyses were performed with the use of Stata/IC software, version 12.0 (StataCorp). 


\begin{tabular}{|c|c|c|c|c|}
\hline Outcome & $\begin{array}{l}\text { Nasal-Cannulae Group } \\
\qquad(N=152)\end{array}$ & $\begin{array}{l}\text { CPAP Group } \\
(\mathrm{N}=151)\end{array}$ & $\begin{array}{l}\text { Risk Difference } \\
(95 \% \mathrm{CI}) * \\
\text { percentage points }\end{array}$ & P Value \\
\hline \multicolumn{5}{|l|}{$\begin{array}{l}\text { Reason for treatment failure }- \text { no./ } \\
\text { total no. }(\%) \dagger\end{array}$} \\
\hline Apnea & $32 / 52(61.5)$ & $25 / 39(64.1)$ & $-2.6(-22.6$ to 17.5$)$ & 0.80 \\
\hline $\begin{array}{l}\text { Increase in fraction of inspired } \\
\text { oxygen }\end{array}$ & $21 / 52(40.4)$ & $20 / 39(51.3)$ & $-10.9(-31.5$ to 9.7$)$ & 0.30 \\
\hline Respiratory acidosis & $6 / 52(11.5) \ddagger$ & $2 / 39(5.1)$ & $6.4(-4.7$ to 17.5$)$ & 0.29 \\
\hline Urgent need for intubation & $2 / 52(3.8)$ & $4 / 39(10.3)$ & $-6.4(-17.3$ to 4.5$)$ & 0.22 \\
\hline $\begin{array}{c}\text { Reintubation within } 7 \text { days after } \\
\text { extubation - no. (\%) }\end{array}$ & $27(17.8)$ & $38(25.2)$ & $-7.4(-16.6$ to 1.8$)$ & 0.12 \\
\hline 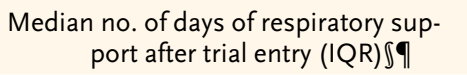 & 34 (7 to 55$)$ & 38 (11 to 57$)$ & NA & 0.44 \\
\hline $\begin{array}{l}\text { Median no. of days of oxygen therapy } \\
\text { after trial entry (IQR) }\|\|\end{array}$ & $38(0$ to 78$)$ & 49 (8 to 83$)$ & NA & 0.15 \\
\hline $\begin{array}{c}\text { Median weight gain during first } 7 \text { days } \\
\text { after extubation (IQR) }-\mathrm{g}\end{array}$ & $20(-42$ to 79.5$)$ & $10(-54$ to 75$)$ & NA & 0.39 \\
\hline Median discharge weight (IQR) — gी & 2886 (2515 to 3290$)$ & 2950 (2500 to 3524$)$ & NA & 0.53 \\
\hline $\begin{array}{l}\text { Median no. of days in a tertiary care } \\
\text { center (IQR) } 9\end{array}$ & 65 (43 to 91$)$ & 64 (45 to 104$)$ & NA & 0.56 \\
\hline Median no. of days in any hospital (IQR) & 79 (63 to 105$)$ & $84(65$ to 106$)$ & NA & 0.38 \\
\hline
\end{tabular}

* Positive values favor the CPAP group, and negative values favor the nasal-cannulae group.

$\dagger$ Treatment may have failed for more than one reason. In one infant in the CPAP group, treatment failed because a set pressure of more than $8 \mathrm{~cm}$ of water was prescribed during the primary-outcome period.

tOne infant had a measured $\mathrm{pH}$ of exactly 7.20, and one infant had a measured $\mathrm{pH}$ of 7.21.

$\int$ Respiratory support included the use of high-flow nasal cannulae, nasal CPAP, nonsynchronized nasal intermittent positive-pressure ventilation, and mechanical ventilation through an endotracheal tube.

II Infants who died before discharge were excluded.

\| This category includes only hospital days, even though some infants received oxygen therapy after being discharged.

\section{RESULTS}

\section{STUDY PATIENTS}

A total of 303 infants underwent randomization (152 to the nasal-cannulae group and 151 to the CPAP group) during the study period (Fig. 1). The demographic and clinical characteristics of the mothers and infants in the two groups were similar (Table 1).

\section{PRIMARY OUTCOME}

The use of high-flow nasal cannulae was found to be noninferior to the use of nasal CPAP by our definition, with treatment failure occurring in 52 of 152 infants (34.2\%) in the nasal-cannulae group and 39 of 151 infants (25.8\%) in the CPAP group (risk difference, 8.4 percentage points; $95 \%$ confidence interval, -1.9 to 18.7). Treatment failure stratified according to gestational-age subgroup is provided in Table S1 in the Supplementary Appendix, available at NEJM.org.
The most common reason for treatment failure in the two study groups was apnea (Table 2), with no significant between-group difference in the reason for failure. Failure was most likely to occur during the first day after extubation in the two groups (Fig. 2).

\section{REINTUBATION DURING THE FIRST 7 DAYS AFTER EXTUBATION}

Of the 52 infants in whom treatment with highflow nasal cannulae failed during the first 7 days after extubation, 25 (48\%) were successfully treated with nasal CPAP or nonsynchronized nasal intermittent positive-pressure ventilation without reintubation. Thus, only $17.8 \%$ of infants in the nasal-cannulae group were reintubated, as compared with $25.2 \%$ of those in the CPAP group $(\mathrm{P}=0.12)$ (Table 2). In the latter group, 3 infants received nonsynchronized nasal intermittent positive-pressure ventilation immediately after extubation, and 36 infants (23.8\%) received non- 
synchronized nasal intermittent positive-pressure ventilation during the first 7 days after extubation; of these infants, 22 were reintubated after treatment failure.

\section{OTHER SECONDARY OUTCOMES AND ADVERSE EVENTS}

There were no significant between-group differences in rates of other secondary outcomes (Table 2) or in rates of death or other serious adverse events (Table 3). The pneumothorax rate after trial entry was low in the two study groups. In the nasal-cannulae group, infants had a significantly lower incidence of nasal trauma than those in the CPAP group ( $39.5 \%$ vs. $54.3 \%, \mathrm{P}=0.01$ ), and fewer infants required a change in therapy because of nasal trauma $(\mathrm{P}=0.001)$. No infant in either group required surgical correction for nasal trauma. Almost half the cases of nasal trau$\mathrm{ma}$ in the nasal-cannulae group were diagnosed while the infants were receiving other types of noninvasive respiratory support. If the diagnosis of nasal trauma was limited to cases that were diagnosed during the assigned treatment, the between-group difference was greater, with a rate of $19.1 \%$ in the nasal-cannulae group versus $53.0 \%$ in the CPAP group $(\mathrm{P}<0.001)$.

\section{DISCUSSION}

On the basis of our prespecified definition of noninferiority, the use of high-flow nasal cannulae was noninferior to the use of nasal CPAP as respiratory support for very preterm infants after extubation, with a between-group difference of 8.4 percentage points that favored CPAP. When treatment with high-flow nasal cannulae failed, about half the infants were successfully treated with CPAP without reintubation, resulting in a nonsignificant between-group difference in the rate of reintubation within 7 days after extubation. Among infants in the nasal-cannulae group, there was no increase in rates of death or complications and there was a decrease in the rate of nasal trauma, as compared with the CPAP group.

The use of high-flow nasal cannulae has been widely adopted without evidence of safety and efficacy. The results of two small, randomized trials of these devices, as compared with nasal CPAP, after extubation have been reported previously. Both these trials were conducted in a single center and had a superiority design. In the study by Campbell et al.,15 40 infants with a birth weight of less than $1250 \mathrm{~g}$ were randomly assigned to

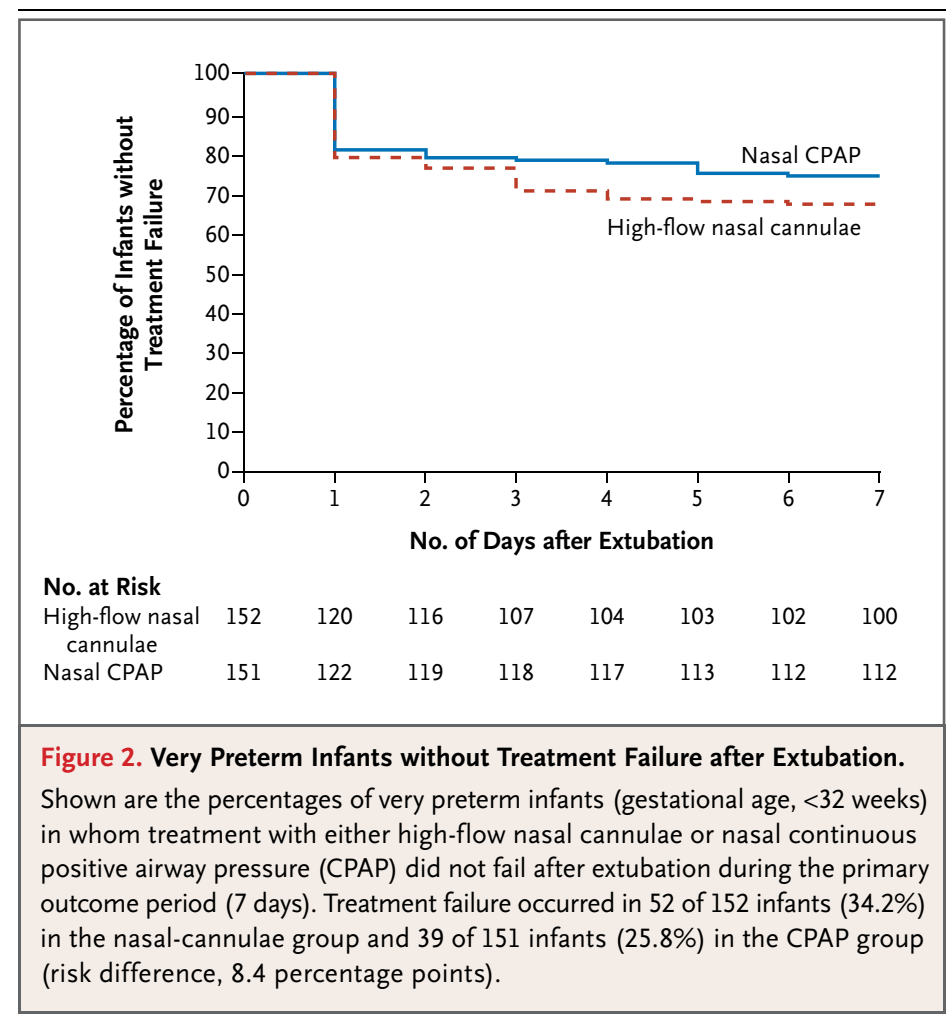

one of the two treatments after extubation. Significantly more infants in the nasal-cannulae group required reintubation within 7 days, probably because of the reduced flow rates $(<2$ liters per minute) that were used. In the study by Collins et al., ${ }^{16}$ which involved 132 very preterm infants, the investigators used a different high-flow nasal-cannulae device (Vapotherm) and an increased flow rate (8 liters per minute) after extubation. They found no significant between-group difference in the primary outcome of treatment failure within 7 days and no significant difference in reintubation rates, although the authors acknowledged that the study was underpowered for these outcomes. Nasal-trauma scores were lower in the nasal-cannulae group than in the CPAP group, which is consistent with our findings.

In our multicenter trial, 63 of the infants had a gestational age of less than 26 weeks, but the study was not powered to evaluate the efficacy or safety of high-flow nasal cannulae in this extremely preterm subgroup. The treatment-failure rate was very high among these infants, regardless of the assigned treatment, and the risk difference was 20 percentage points in favor of nasal CPAP (see the Supplementary Appendix). Given this finding, we think that clinicians should be 


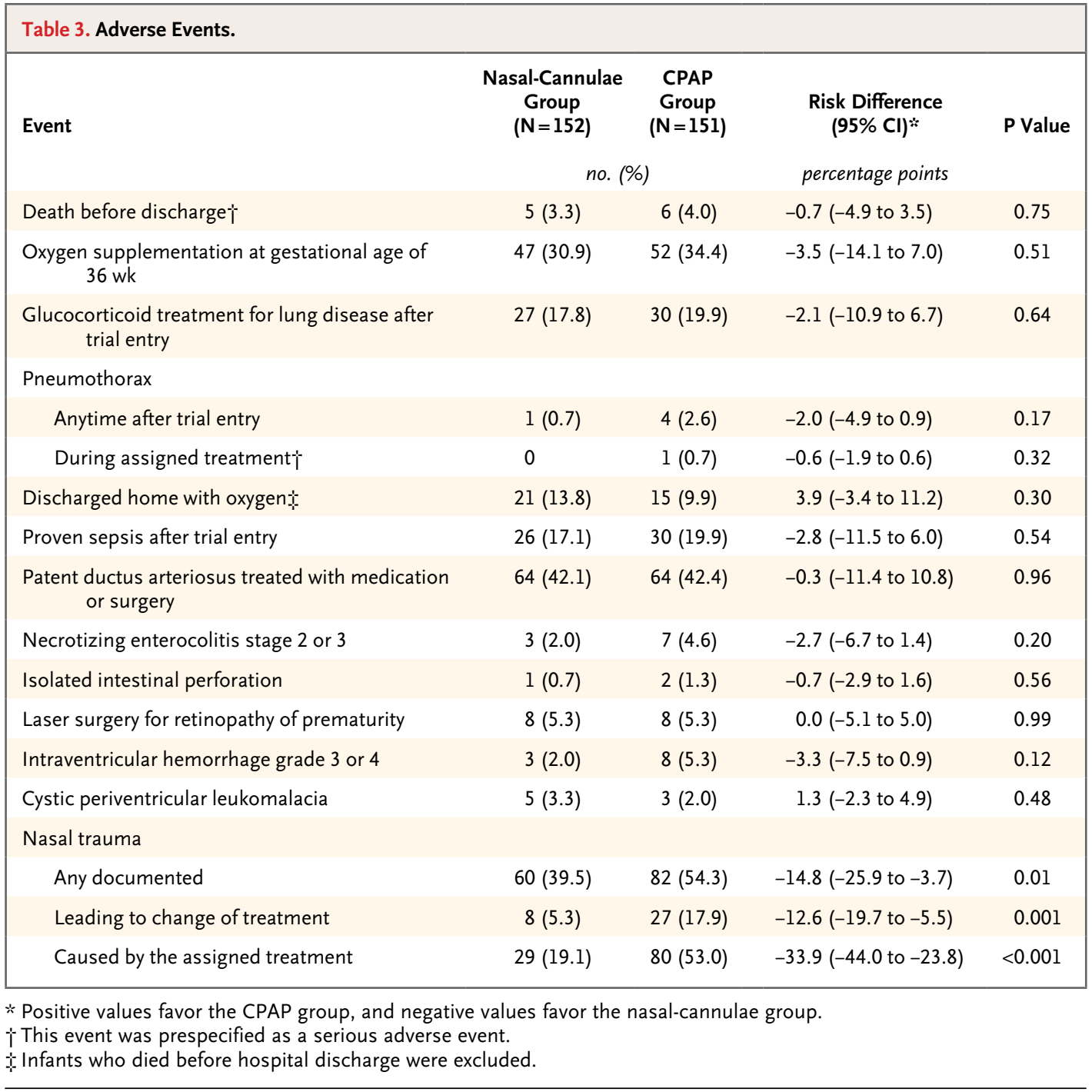

cautious before using high-flow nasal cannulae as first-line respiratory support in extremely preterm infants after extubation. The risk difference for treatment failure among infants with a gestational age of 26 weeks or more was 5 percentage points.

The results of our trial pertain only to infants who have been extubated and should not be extrapolated to the use of high-flow nasal cannulae as primary respiratory support after birth. We used the Fisher \& Paykel high-flow nasal-cannulae system in our trial, but there is no evidence that any one commercially available system is superior to another. ${ }^{17}$ The flow rates for the nasal cannulae that we used have been shown to result in distending pressures in vivo that are similar to, or slightly lower than, commonly set nasal CPAP pressures. ${ }^{18-20}$ Since it was not possible to blind the intervention, we used prespecified, objective criteria for treatment failure as the primary outcome to minimize bias.

We allowed the use of rescue nasal CPAP in the nasal-cannulae group only after treatment failure. We acknowledge that this may have influenced some of the secondary outcomes in the nasalcannulae group. Because the use of nasal CPAP prevented the reintubation of almost half the infants in whom treatment with nasal cannulae had failed, it seems reasonable to use high-flow nasal cannulae initially after extubation if both therapies are available. In our trial, nonsynchronized nasal intermittent positive-pressure ventilation could be used in infants receiving nasal CPAP. If the use of nonsynchronized nasal intermittent positive- 
pressure ventilation had not been permitted until nasal CPAP had failed, the risk difference for the primary outcome might have been smaller.

When appraising the result of a noninferiority trial, both the risk difference and its $95 \%$ confidence interval are considered. Although our best estimation of the risk difference was 8.4 percentage points, we acknowledge that the upper limit of the $95 \%$ confidence interval was close to the margin of noninferiority (20 percentage points) and that slightly different failure rates in either group could have altered our conclusions.

Further research on the use of high-flow nasal cannulae in preterm and term newborn infants is required. Since such cannulae are used with increasing frequency in the nontertiary care setting, randomized trials of high-flow nasal cannulae as primary respiratory support from birth will be important. We conclude that treatment with high-flow nasal cannulae was noninferior to the use of nasal CPAP as respiratory support after extubation in very preterm infants. Since our trial was underpowered to show noninferiority in infants with a gestational age of less than 26 weeks, the use of high-flow nasal cannulae as first-line respiratory support after extubation in this extremely preterm group requires caution.

Supported by a program grant (606789) and a Centre for Clinical Research Excellence grant (546519) from the National Health and Medical Research Council.

Disclosure forms provided by the authors are available with the full text of this article at NEJM.org.

We thank the patients' families and the staff members who cared for them at the three participating centers, and research nurses Connie Wong, Donna Hovey, Louise Goodchild, and Ros Lontis for their assistance in recruitment and data collection.

\section{REFERENCES}

1. Hamilton BE, Martin JA, Ventura SJ. Births: preliminary data for 2011. National vital statistics reports. Vol. 61. No. 5. Hyattsville, MD: National Center for Health Statistics, 2012. (DHHS publication no. (PHS) 2013-1120.)

2. Davis P, Henderson-Smart D. Postextubation prophylactic nasal continuous positive airway pressure in preterm infants: systematic review and meta-analysis. J Paediatr Child Health 1999;35:367-71.

3. Hough JL, Shearman AD, Jardine LA, Davies MW. Humidified high flow nasal cannulae: current practice in Australasian nurseries, a survey. J Paediatr Child Health 2012;48:106-13.

4. Manley BJ, Owen L, Doyle LW, Davis PG. High-flow nasal cannulae and nasal continuous positive airway pressure use in non-tertiary special care nurseries in Australia and New Zealand. J Paediatr Child Health 2012;48:16-21.

5. Nath P, Ponnusamy V, Willis K, Bissett L, Clarke P. Current practices of high and low flow oxygen therapy and humidification in UK neonatal units. Pediatr Int 2010;52:893-4.

6. Hochwald $\mathrm{O}$, Osiovich $\mathrm{H}$. The use of high flow nasal cannulae in neonatal intensive care units: is clinical practice consistent with the evidence? J Neonat Perinat Med 2010;3:187-91.

7. Holleman-Duray D, Kaupie D, Weiss
MG. Heated humidified high-flow nasal cannula: use and a neonatal early extubation protocol. J Perinatol 2007;27: 776-81.

8. Shoemaker MT, Pierce MR, Yoder BA, DiGeronimo RJ. High flow nasal cannula versus nasal CPAP for neonatal respiratory disease: a retrospective study. J Perinatol 2007;27:85-91.

9. Wilkinson D, Andersen C, O'Donnell CP, De Paoli AG. High flow nasal cannula for respiratory support in preterm infants. Cochrane Database Syst Rev 2011; 5:CD006405.

10. Manley BJ, Dold SK, Davis PG, Roehr CC. High-flow nasal cannulae for respiratory support of preterm infants: a review of the evidence. Neonatology 2012;102: 300-8.

11. Shaffer TH, Alapati D, Greenspan JS, Wolfson MR. Neonatal non-invasive respiratory support: physiological implications. Pediatr Pulmonol 2012;47:837-47.

12. Finer NN. Nasal cannula use in the preterm infant: oxygen or pressure? Pediatrics 2005;116:1216-7.

13. Finer NN, Mannino FL. High-flow nasal cannula: a kinder, gentler CPAP? J Pediatr 2009;154:160-2.

14. Piaggio G, Elbourne DR, Altman DG, Pocock SJ, Evans SJ. Reporting of noninferiority and equivalence randomized trials: an extension of the CONSORT state- ment. JAMA 2006;295:1152-60. [Erratum, JAMA 2006;296:1842.]

15. Campbell DM, Shah PS, Shah V, Kelly EN. Nasal continuous positive airway pressure from high flow cannula versus Infant Flow for preterm infants. J Perinatol 2006; 26:546-9.

16. Collins CL, Holberton JR, Barfield C, Davis PG. A randomized controlled trial to compare heated humidified high-flow nasal cannulae with nasal continuous positive airway pressure postextubation in premature infants. J Pediatr 2012;162(5): 949.e1-954.e1.

17. Miller SM, Dowd SA. High-flow nasal cannula and extubation success in the premature infant: a comparison of two modalities. J Perinatol 2010;30:805-8.

18. Spence KL, Murphy D, Kilian C, McGonigle R, Kilani RA. High-flow nasal cannula as a device to provide continuous positive airway pressure in infants. J Perinatol 2007;27:772-5.

19. Kubicka ZJ, Limauro J, Darnall RA. Heated, humidified high-flow nasal cannula therapy: yet another way to deliver continuous positive airway pressure? Pediatrics 2008;121:82-8.

20. Wilkinson DJ, Andersen CC, Smith K, Holberton J. Pharyngeal pressure with high-flow nasal cannulae in premature infants. J Perinatol 2008;28:42-7.

Copyright (C) 2013 Massachusetts Medical Society. 